\title{
Operant rate in the turtle as a function of temperature'
}

\author{
F. T. Crawford and Lynne E. Siebert ${ }^{2}$ \\ FLORIDA STATE UNIVERSITY
}

\begin{abstract}
Fresh water turtles were trained to press a lever for food reinforcement. Sessions were conducted in a test chamber containing water which varied from $58^{\circ}$ to $85^{\circ} \mathrm{F}$. Individual response rates were not identical, but the functions tended to be parallel.
\end{abstract}

\section{Problem}

Research among reptiles has been conducted primarily upon the turtle because of their accessibility and ease of maintenance and handling in the laboratory. Perhaps a principal determinant of the use of the turtle for psychological research is the fact that unlike other reptiles the turtle eats readily under conditions of captivity, responding well to the presentation of reinforcement.

Operant conditioning techniques have been extensively used to study the behavior of a variety of animals in a multitude of applications, but there is only one report of successful operant conditioning with the turtle, and this was done under conditions of air deprivation (Van Sommers, 1963). The purpose of the present research was two-fold: to develop an operant technique with food reinforcement; and since turtles are exothermal, to investigate operant rate as a function of temperature.

\section{Method}

Ss were four mature female Florida cooters( Pseudemys floridana suwanniensis) which had been maintained in the laboratory for an extended period of time. They were observed to eat regularly and to be well adapted to their living conditions. Ss were selected so that they were similar to each other in size and weight. The shell length and width of three of the turtles was $7 \times 6$ in and the fourth measured $71 / 2 \times 6$ in. The weights of the turtles ranged from $1 \mathrm{lb}, 9 \mathrm{oz}$ to $1 \mathrm{lb}, 15 \mathrm{oz}$.

Ss were trained to press a lever situated within an aluminum test chamber having a height, length, and width of 9,18 , and 12 in, respectively. Prior to testing Ss, the temperature of the water from the home tank was determined, and an amount of water was removed and placed in the test chamber sufficient to fill it to a depth of $3 / 4$ in. Each $\mathrm{S}$ was removed from the home tank, placed in the test chamber, and given $10 \mathrm{~min}$. of continuous reinforcement. Reinforcement, a $1 / 8$ in cube of cooked shrimp, was delivered by a Gebrands Universal Feeder.

Testing was carried out over an 84-day period. The range of water temperatures occurring within thatperiod was from $58^{\circ}$ to $85^{\circ} \mathrm{F}$.

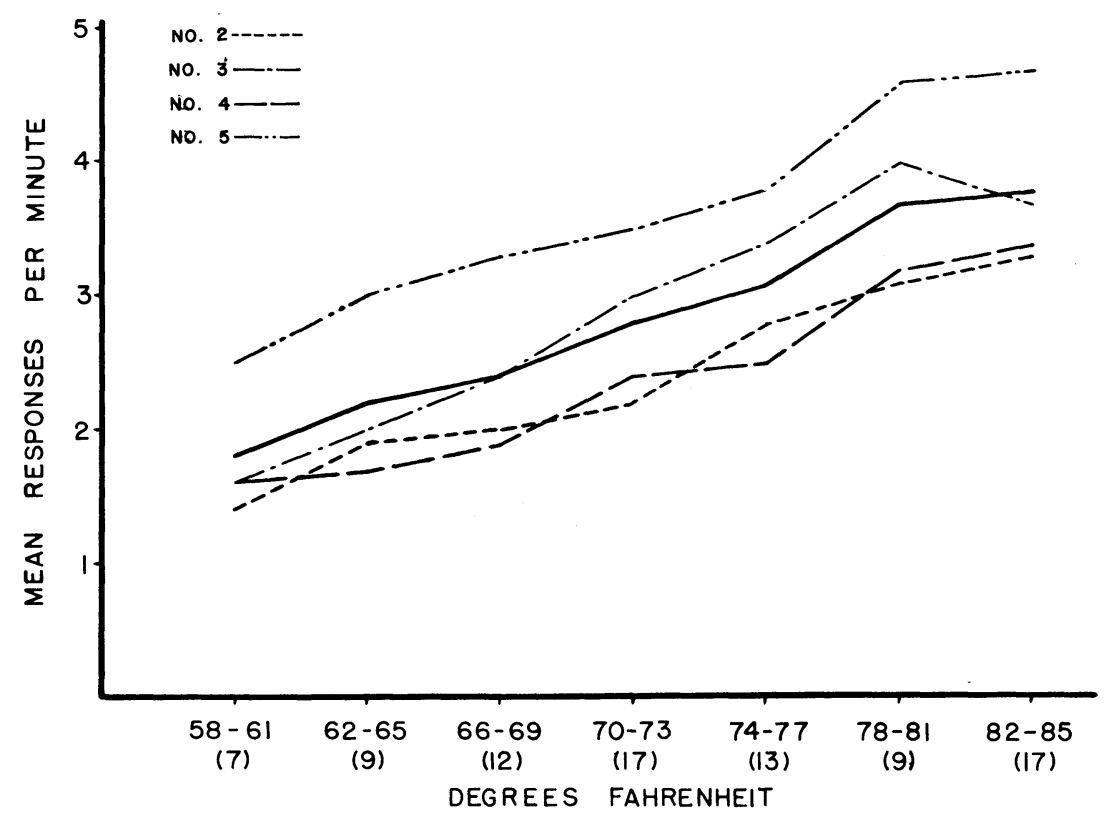

Fig. 1. Mean response rate as a function of degrees water temperature. 


\section{Results}

The method and apparatus employed resulted in rapid acquisition of the bar press response. Shaping of the response occurred within the first few minutes of the initial test session. A single failure in obtaining operant conditioning was with a turtle, not included in the present experiment, whose size hindered feeding in the limited depth of water and the restricted area of the test chamber.

The relationship between operant rate and water temperature is shown in Fig. 1. Each point represents a range of $4^{\mathrm{O}} \mathrm{F}$. The number of daily observations occurring for each temperature range is indicated by the numbers appearing in parentheses. The heavier line in the figure represents the combined performance of the four Ss. The operant rates for the individual Ss are not identical but they are relatively uniform and consistent, and the individual curves tend to parallel each other. Although each of the lines continues to rise at the higher temperatures, with the exception of the final point for S No. 3 , it is probably better to assume that there would be observed an eventual decline in rate with even higher temperatures, since the $85^{\circ} \mathrm{F}$ water temperature corresponds to an air temperature of $95^{\circ} \mathrm{F}$ under the conditions tested. Higher water and air temperatures would eventually approach lethal limits.
The body temperature of turtles, being exothermal, tends to conform to that of the environment and is related to metabolic rate. This relationship is commonly expressed as a factor by which metabolic rate increases with a temperature rise of $10^{\circ} \mathrm{C}$ and is referred to as the $\mathrm{Q}_{10}$ approximation. According to Prosser \& Brown (1961), this factor lies between 2.0 and 2.5. Van Sommers (1963) reported an increase in response rate close to a factor of 2 for the temperature range of $22-32^{\circ} \mathrm{C}$ $\left(70.6-89.6^{\circ} \mathrm{F}\right)$ employed in his study. In the present study, the factor was approximately $1.6(1.42-1.79)$ for a similar temperature range of $66-85^{\circ} \mathrm{F}$. The fact that essentially linear rates were produced with a temperature range about one-third larger than that employed by Van Sommers indicates that an operant response for food reinforcement is highly reliable method for the behavioral study of the turtle.

\section{References}

PROSSER, C. L., \& BROWN, F. H. Comparative animal physiology. (2nd ed.) Philadelphia: Saunders, 1961. VAN SOMMERS, P. Air-motivated behavior in the turtle. J. comp. physiol. Psychol., 1963, 56, 590-596.

\section{Notes}

1. Supported in part by a grant-in-aid from the Florida State University Research Council.

2. Now at North Carolina State College.

\begin{abstract}
ERIKSEN, C. W., \& STEFFY, R. A. (U. Illinois \& Veterans Administration Hospital, Danville, Illinois). Short term memory and retroactive interference in visual perception. J. exp. Ps y c hol., in press. - 3 experiments were performed on the relation of backward masking effects in visual perception and short term perceptual memory. In all experiments the 1st stimulus was a brief presentation of a display consisting of a random pattern of Xs and Os arranged in a circular pattern. At predetermined intervals after termination of the display (10-700 $\mathrm{ms})$ an arrow appeared indicating a position on the preceding display and $S$ reported whether the position had contained an $\mathrm{X}$ or $\mathrm{O}$. Experiment 1 in addition to an age variable, studied the effect of an illuminated indicator field. Experiment 2 was similar to Experiment 1 except that possible brightness summation between display and indicator stimuli was eliminated.
\end{abstract}

Experiment 3 was essentially a replication of Experiment 2 using 4 practiced Ss on whom sufficient observations were obtained to analyze the Ss' functions individually.

In none of the experiments was any evidence found of a brief perceptual memory. Experiment 1 showed impaired performance when indicator followed display within $100 \mathrm{~ms}$. These results were consistent with an interpretation in terms of brightness summation between display and indicator fields with resulting loss of figure-ground contrast for display symbols. Experiment 2 confirmed this interpretation since elimination of possibility of brightness summation resulted in no significant effect attributable to delay of the indicator. Experiment 3 indicated marked individual differences in retroactive interference functions occasioned by the delay of the indicator. (Pre-publication copies available from the authors.) 